\title{
Pathum Raksa Project: Addressing Disparity in Breast Cancer Care Through National Innovation in Thailand
}

\author{
Supinda Koonmee (D)' \\ Ongart Somintara ${ }^{2}$ \\ Piyapharom Intarawichian (I) \\ Chaiwat Aphivatanasiri (DD' \\ Sakkarn Sangkhamanon (iD) \\ Suphawat Laohawiriyakamol ${ }^{3}$ \\ Rujira Panawattanakul ${ }^{4}$ \\ Phanchanut Mahantassanapong ${ }^{5}$ \\ Chayanoot Rattadilok ${ }^{6}$ \\ Piyarat Jeeravongpanich ${ }^{7}$ \\ Wilart Krongyute ${ }^{8}$ \\ Krisada Prachumrasee (iD 9 \\ Reza Alaghehbandan $\mathbb{D}^{10}$
}

'Department of Pathology, Faculty of Medicine, Khon Kaen University, Khon Kaen, Thailand;

${ }^{2}$ Department of Surgery, Faculty of Medicine,

Khon Kaen University, Khon Kaen, Thailand;

${ }^{3}$ Division of General Surgery, Faculty of Medicine, Prince of Songkla University,

Songkhla, Thailand; ${ }^{4}$ Department of Surgery,

Udonthani Hospital, Udonthani, Thailand;

${ }^{5}$ Department of Anatomical Pathology, Surin

Hospital, Surin, Thailand; ${ }^{6}$ Department of

Surgery, Nopparatrajathanee Hospital,

Bangkok, Thailand; ${ }^{7}$ Anatomical Pathology Unit,

Songkhla Hospital, Songkhla, Thailand;

${ }^{8}$ Department of Surgery, Fort Suranari Hospital, Nakhon Ratchasima, Thailand; ${ }^{9}$ The

College of Local Administration, Khon Kaen University, Khon Kaen, Thailand; ${ }^{10}$ Department of Pathology, Faculty of Medicine, University of British Columbia, Royal Columbian Hospital,

Vancouver, BC, Canada

Correspondence: Chaiwat Aphivatanasiri Department of Pathology, Faculty of Medicine, Khon Kaen University, Khon Kaen, Thailand

Email chaiap@kku.ac.th

Reza Alaghehbandan

University of British Columbia, Royal

Columbian Hospital, Vancouver, BC,

Canada

Email reza.alagh@gmail.com
Purpose: Breast cancer is a growing public health challenge in Thailand. Pathum Raksa project was launched in 2015, as a result of higher than expected rate of triple-negative breast cancers in Thai women. The purpose of this project was to identify the cause(s) and address the issue(s), hence improving the quality of breast cancer biomarker testing in Thailand.

Materials and Methods: Nineteen hospitals across the country, with 902 breast cancer patients were enrolled in this study during 2015-2020. The pre- and post-data from Pathum Raksa initiative was only available for Khon Kaen University (KKU) and Udonthani hospitals in Northeast Thailand. We developed a resource-stratified strategic plan that included designing a unique specimen container, forming multidisciplinary teams from the Surgery and Pathology Departments, and employing locally developed innovative technologies to optimize the entire process of breast cancer diagnostics and biomarker testing.

Results: The rate of triple-negative breast cancers in KKU and Udonthani decreased $52.8 \%$ $(p=0.02)$ and $28.9 \%(p=0.48)$, respectively. The rate of ER+ breast cancers in both hospitals increased 5\% post-Pathum Raksa implementation. The rate of HER2-neu+ (score 3+) also increased in both hospitals (particularly an increased $65 \%$ rate in $\mathrm{KKU}$ ). Luminal $\mathrm{A} / \mathrm{B}$ cancers were the most common subtype in both KKU and Udonthani hospitals.

Conclusion: Pathum Raksa project has significantly improved breast cancer biomarker testing in Thailand. As a result of this national innovation, false-negative rates of breast biomarkers have significantly decreased, resulting in improving prognosis, treatment, and survival of breast cancer women in Thailand.

Keywords: breast cancer, biomarkers, Pathum Raksa, multidisciplinary teams, pre-analytical phase

\section{Introduction}

Breast cancer is the most common malignancy in women globally and is a growing public health challenge, especially in economically underdeveloped and developing countries. ${ }^{1}$ Breast cancer deaths disproportionately affect individuals in low-income and middle-income countries, where most breast cancer deaths occur prematurely (in women younger than 70 years old). ${ }^{1}$ In Thailand, breast cancer incidence is significantly increasing in all regions across the country, ranging from $3 \%$ to $7 \%$ increases per year. ${ }^{2}$ Breast cancer is the most common cancer among Thai women and is expected to remain one of the leading to cancer diagnosis through to $2025 .^{2}$

Laboratory services are an integral part of clinical decision-making and contribute to various aspects of health services including cancer diagnostic, therapeutic 
decision-making, disease monitoring, and prevention. ${ }^{3}$ Early diagnosis and accurate histologic interpretation of breast tumors are fundamental pillars of any breast cancer care program. It is well-known fact, that biomarker testing, ER (estrogen receptor), PR (progesterone receptor), and HER2/neu (human epidermal growth factor receptor 2), are of utmost importance for correct patient therapy, where anti-hormonal and HER2-targeted therapies provide significant clinical benefit. ${ }^{4,5}$ Immunohistochemical assays for breast biomarkers are the current standard of care, however, these biomarkers must be appropriately validated, reproducibly performed, correctly interpreted, and reliably reported on specimens that have been handled properly in order to preserve both antigenicity and morphology. 5

Pathum Raksa project, which literally means "Better Breast Cancer Treatment", was launched in 2015, as a result of a higher than the expected rate of triple-negative breast cancers in Thai women. The initial purpose of this project was to identify the cause(s) and address the issue (s), hence improving the quality of breast cancer biomarker testing in Thailand. This paper will outline how this national innovative initiative was successfully implemented and has positively impacted the lives of Thai breast cancer patients.

\section{Country Profile}

With a population of nearly 70 million, Thailand is considered a middle-income country located in Southeast Asia. As per the most recent 2020 World Health Organization (WHO) statistics, the age-standardized (world) incidence and mortality rates for breast cancers among Thai women are 37.8 and 12.7 per 100,000 population. $^{6}$ Estimated past and future trends in total breast cancers per year are from 13,000 in 2012 to 23,000 cases in $2040 .^{6}$ Thailand is a diverse country in many aspects including demographics, geography, socioeconomic, and culture, leading to variable region-specific

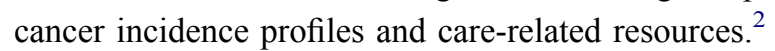

National breast cancer screening campaigns were introduced in 2002 and the Thai government promoted guidelines concerning self-breast examinations and clinical breast exams. $^{2}$ It is estimated that there are nearly 2800 CT, MRI, and mammography machines in Thailand, with close to $25 \%$ located in the capital Bangkok, and the remaining across the 76 provinces. ${ }^{2}$ Further, approximately one-third of these machines are in private sectors and not available to the majority of the Thai women population, who are covered under the universal health coverage program. ${ }^{2}$

Most pathology laboratories in Thailand are hospitalbased and challenged with increasing workload and staff shortages. $^{7}$ In Thailand, there are more than 300 hospitals performing breast surgeries, where the specimens are either examined by in-house pathology laboratories or outsourced. It should be noted that there are only 32 pathology laboratories across the country that are officially certified and accredited by the Royal Committee of Pathologists of Thailand. The certification also includes immunohistochemistry (for ER, PR, and HER2-neu) and in situ hybridization (ISH) for HER2-neu testing. ${ }^{8}$

The varying resources for pathology laboratories across the country can potentially lead to cancer care diagnostics and treatment disparity due to the variation in personnel, infrastructure, expertise and experience. Table 1 presents the geographic distribution of Anatomical Pathologists per 100,000 population in Thailand (source: The Royal Committee of Pathologists of Thailand). It is evident that the rate of anatomical pathologists per 100,000 population for the capital Bangkok $(3.8 / 100,000)$ is comparable to other economically developed countries such as the USA (3.9/100,000) and Canada $(4.8 / 100,000) .{ }^{9}$ However, there

Table I Distribution of Anatomical Pathologists per 100,000 Population in Thailand (Source: The Royal Committee of Pathologists of Thailand)

\begin{tabular}{|l|c|c|c|c|c|}
\hline Regions & Retired & Active & Total & Population & Active Pathologists per 100,000 Population \\
\hline Bangkok & 78 & 210 & 288 & $5,588,222$ & 3.8 \\
Central & 0 & 14 & 14 & $9,613,128$ & 0.1 \\
East & 5 & 13 & 18 & $4,847,817$ & 0.3 \\
West & 0 & 4 & 4 & $2,794,160$ & 0.1 \\
North & 11 & 51 & 62 & $12,027,271$ & 0.4 \\
Northeast & 7 & 44 & 51 & $21,848,228$ & 0.2 \\
South & 3 & 29 & 32 & $9,467,901$ & 0.3 \\
\hline
\end{tabular}


is a wide gap in the pathologist workforce in the remainder of the country, ranging from 0.1 to 0.4 per 100,000 population, resulting in a significant gap (at least 10 times less) in accessing surgical pathology-related services including breast cancer diagnostics.

\section{Project History and Background}

The original idea of this national initiative began with the senior author (S.K.) observing significant disparity in life expectancy and breast cancer diagnostics quality between economically developed countries and Thailand. In 2003, the senior author (S.K.) and colleagues ${ }^{10}$ carried out a baseline study examining breast cancer immunohistochemical biomarker status (ER/PR, HER2-neu) in Srinagarind Hospital, Khon Kaen University (KKU) affiliated hospital in Northeastern Thailand. The study showed that the rate of ER+ breast cancers in this region was $53.1 \%$, which is significantly lower than the $79-84 \%$ expected ER+ breast cancer rate worldwide. ${ }^{5}$ Additionally, a high rate of triple-negative breast cancers (22\%) was observed in Northeastern Thailand.

These alarming findings led to further investigations, both locally and nationally, to identify the cause(s) of low $\mathrm{ER}+$ and high triple-negative breast cancer rates, by the Royal College of Pathologists of Thailand EQA (External Quality Assurance) program and the "SPHeRE Programme (Scientific Partnership for HER2 Testing Excellence) in Asia-Pacific". All investigations similarly identified gaps in proper tissue fixation as pivotal preanalytic factor.

It should be noted that as per the American Society of Clinical Oncology/College of American Pathologists (ASCO/CAP) practice guidelines, core biopsies of breast tumors are the preferred samples for biomarker testing if they are representative of the tumor (grade and type) at resection. ${ }^{5}$ Unfortunately, this guideline is not consistently followed or practiced across Thailand, mainly due to a lack of infrastructure, resources, and personnel. In small and remote hospitals, mainly located in the "periphery" (away from Bangkok and/or other major university centers) biomarkers testing is mostly performed on surgical specimens, creating pre-analytic challenges resulting in high false-negative biomarker (ER/PR/HER2-neu) results.

Ideally and as per the most recent 2020 ASCO/CAP guidelines, ${ }^{5}$ the time from tissue acquisition to fixation should be as short as possible, and samples for biomarker testing should be fixed in 10\% neutral buffered formalin (NBF) for 6-72 hours. Specimens should also be sliced at 5-mm intervals after appropriate gross inspection and margin designation, and placed in sufficient volume of NBF to allow adequate tissue penetration. Further, when tumors come from remote locations, they should be bisected through the tumor on removed and sent to pathology laboratories immersed in a sufficient volume of NBF. Additionally, a record must be kept for the cold ischemia time, the fixative type, and the time the sample was placed in NBF.

Upon identifying the problem, its scope, and the potential root causes, the research team developed a resourcestratified strategic plan to address the issues in the most affected areas of the country. The plan included designing a unique and specialized specimen container, forming multidisciplinary teams from the Surgery and Pathology Departments, and employing locally developed innovative technologies to optimize the entire process of breast cancer diagnostics and biomarker testing.

\section{Materials and Methods Breast Specimen Container}

To address the issue of poor formalin tissue fixation, a specialized specimen container was designed in 2012 (Figure 1A-C). To the best of our knowledge, this innovative design is the first of its kind to be used in Southeast Asia as well as other low- and middle-income countries.

The container measures $20 \mathrm{~cm}$ (length) $\times 14 \mathrm{~cm}$ (width) $\mathrm{x} 12 \mathrm{~cm}$ (height), with a cover locking system to prevent NBF spills during transportation. The container has the potential to be divided into 2 to 4 compartments, using acrylic barrier plates while maintaining a specimen thickness of $3 \mathrm{~cm}$. The plate design also has at least three $0.5 \mathrm{~cm}$ diameter holes, allowing for the NBF to flow freely between compartments. A customized surgical requisition form was developed, pink paper (compared to routine white paper surgical requisitions), to visually identify the specimen ensuring critical demographic, clinical, and preanalytical factors (Figure 2) are recorded consistently. The specialized breast container is a unique and innovative solution used in Thailand, where most breast specimens come from remote hospitals and need to be transferred to central and major referral pathology laboratories resulting in significant delays before reaching the pathology laboratories. Before the implementation of this specialized specimen container, many samples arrived at the laboratory with poor tissue fixation ultimately leading to potential errors in biomarker testing. 
A

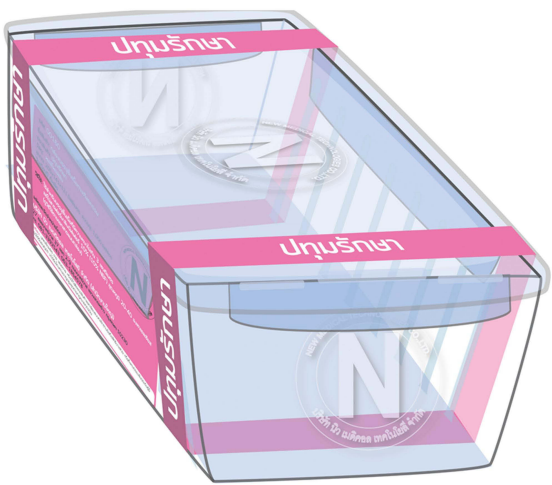

B

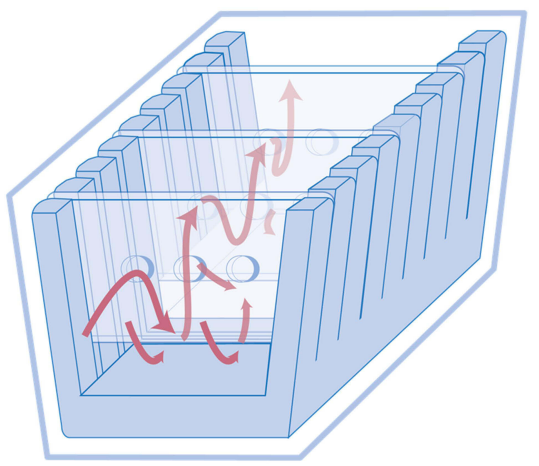

\section{C}

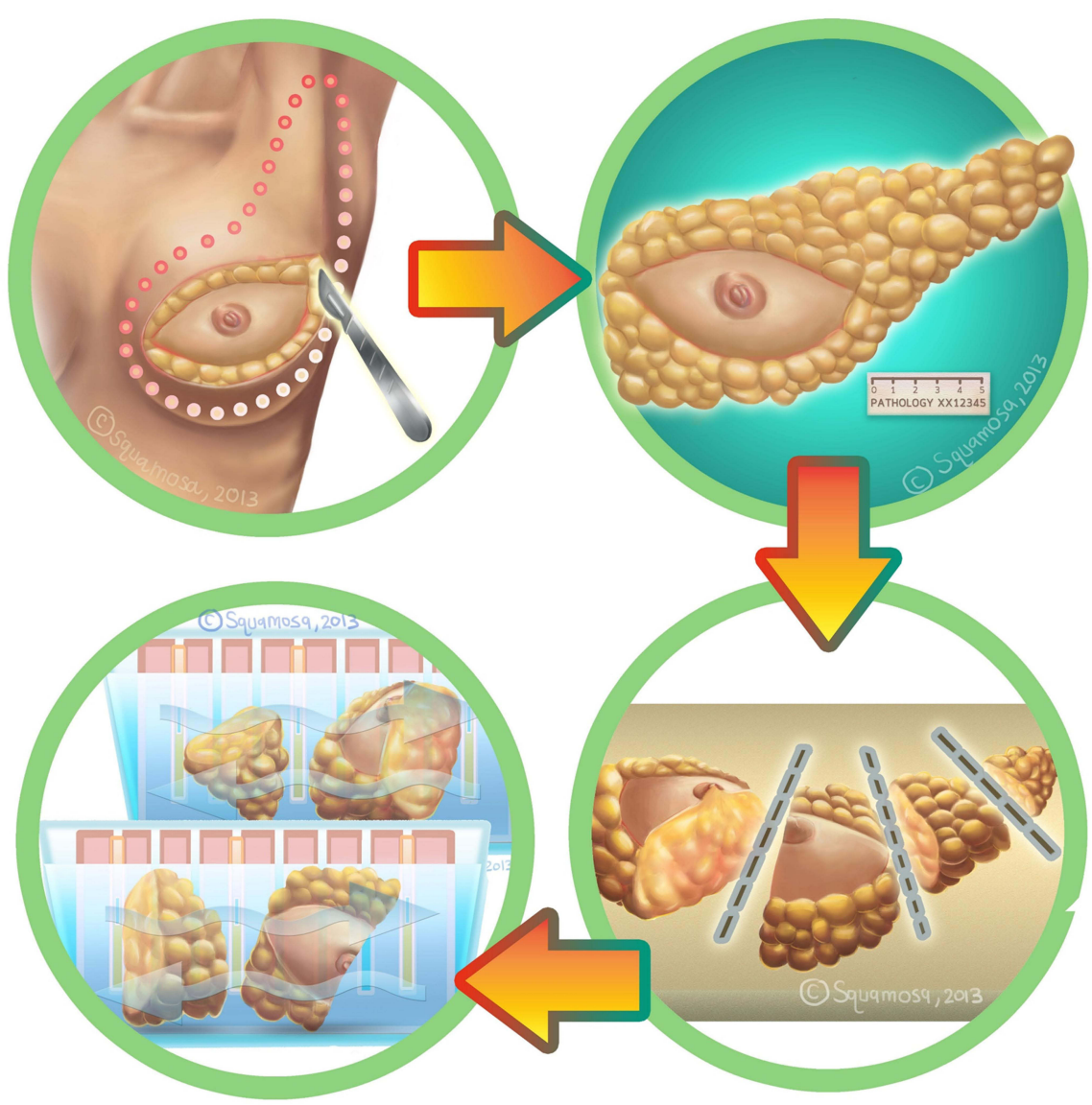

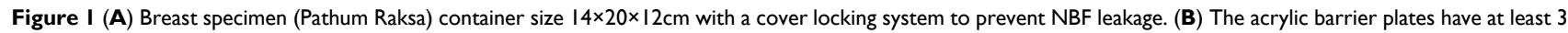
holes measuring in diameter of $0.5 \mathrm{~cm}$, allowing NBF free flow between sections. (C) Breast tumor surgical specimens were serially cut to a thickness of $3 \mathrm{~cm}$ before being placed in the specialized container.

Note: Figure IC used with permission from Thaomani Ruaysoongnern; copyright Squamosa 2013.

\section{Specimen Handling in Operating Room}

In order to place a breast specimen in the container (with multiple compartments), the sample is serially sectioned by the surgeon in 3-4 cm slice thickness, allowing for
NBF tissue penetration (Figure 3). Guidelines were developed to ensure specimen orientation remained intact during specimen transportation within the container from the operating room (OR) to the pathology laboratories. 


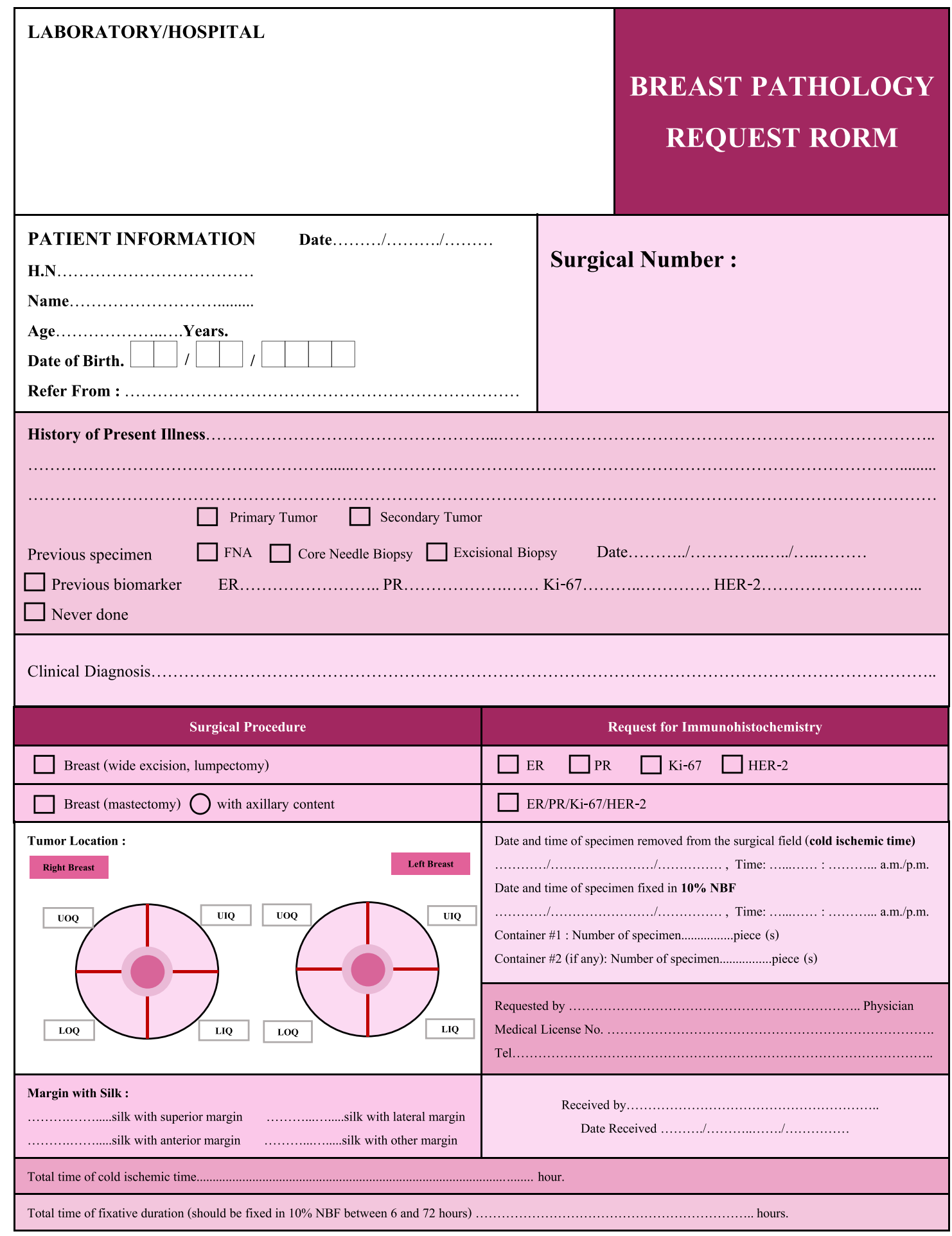

\section{ParHólOGY Developed by Department of Pathology, Faculty of Medicine, Khon Kaen University}

Figure 2 A special surgical request form in a visual pink color for recording data of demographic, clinical, and pre-analytical factors. Note: Figure courtesy of and developed by Department of Pathology, Faculty Medicine, Khon Kaen University. 


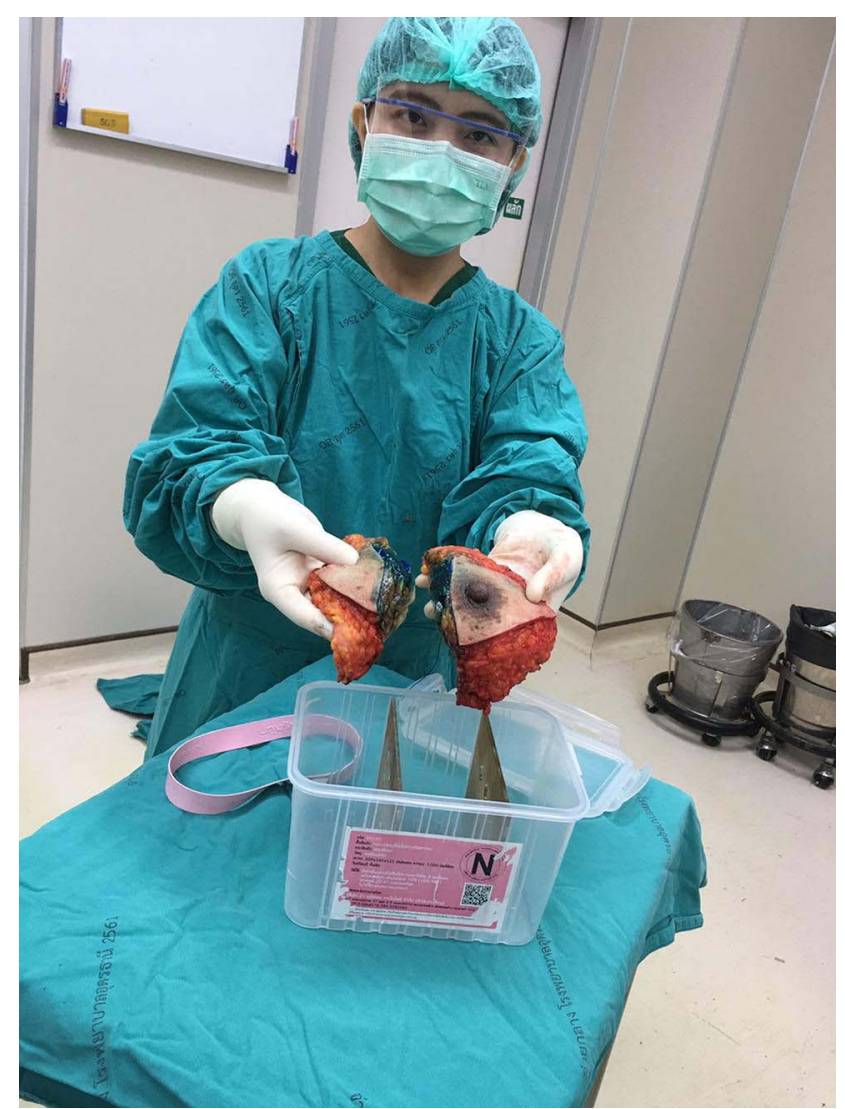

Figure 3 The serial sections of the breast tumor are divided by the acrylic barrier plates.

Mastectomy specimens are oriented by the surgeons marking the superior and lateral margins with a single short and long surgical silk sutures, respectively. For lumpectomy samples, a third suture marks the anterior margin with double surgical silks (Figure 4).

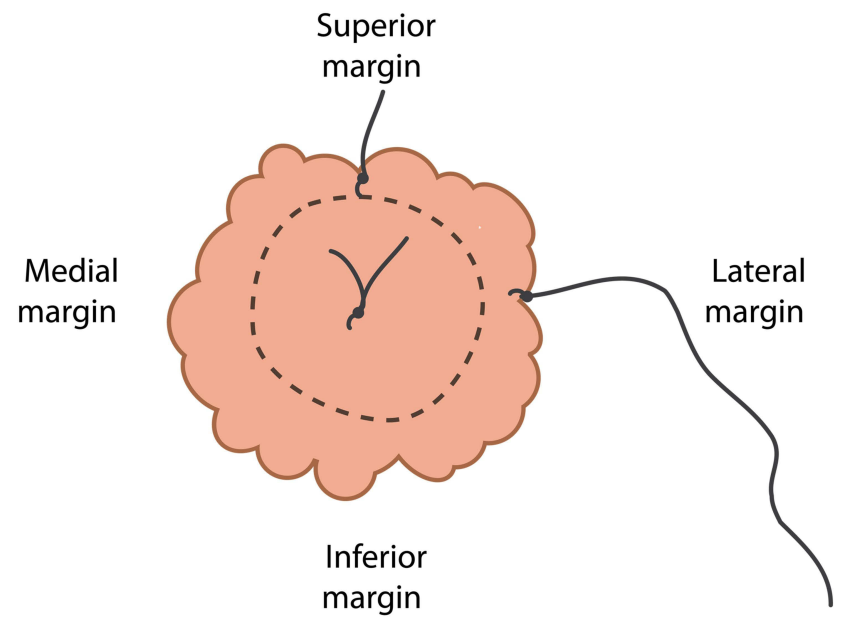

Figure 4 The mastectomy specimen margins are marked superior and lateral with single short and long surgical silk sutures, respectively. For the lumpectomy specimen, the third margin (anterior) is marked with a double surgical silk.

\section{Monitoring Pre-Analytic Factors}

In this study, pre-analytic factors such as cold ischemic time, fixation type, and time of collection are recorded on the surgical requisition form. As per the ASCO/CAP clinical practice guidelines, ${ }^{5}$ samples for biomarker testing should be fixed in NBF between 6 and 72 hours. In some of the hospitals involved in this project, the geographic distance between OR and outsource pathology laboratories is upwards of 300 miles in upcountry hospitals. It was evident that this can result in over-fixation of specimens, which could potentially impact biomarker testing. In order to address this concern, the research team collaborated with the Electrical Engineering Department at KKU, leading to the development of a monitoring tool, based on the Internet of Things (IoT) concept, allowing for monitoring fixation time.

The Internet of Things is a network of physical objects ("things" such as in this case breast container) that are embedded with sensors, software, and other technologies for the purpose of connecting and exchanging data with other devices and systems over the Internet. Further, a notification feature was designed and integrated to assist in notifying laboratory staff of fixation time, preventing potential over-fixation. The notification feature has been proven to be extremely helpful, particularly in laboratories with high workloads and staff shortages. This innovative technology enabled laboratories to prioritize gross examination of breast cancer specimens, by ensuring all specimens were processed before exceeding the recommended 72 hours fixation time.

From a logistical perspective, designed electronic devices are placed and installed both in the OR and pathology laboratories. A tagged breast cancer specimen container is scanned two times by radio frequency identification (RFID) technology reader: 1) after placing the specimen in NBF and before leaving the OR and 2) upon arriving at the pathology laboratory as shown in Figure 5. Once the breast container is initially scanned in the OR, the data (date/time, hospital, container number) is sent to the server and a notification message is sent to laboratory staff. A web-based application tool was also designed for monitoring specimen fixation time (Figure 6).

\section{Project Implementation}

The first step towards a successful implementation of this project required building support and coalitions with the surgeons in order to present the idea of using the specially designed container for better handling of breast cancer 

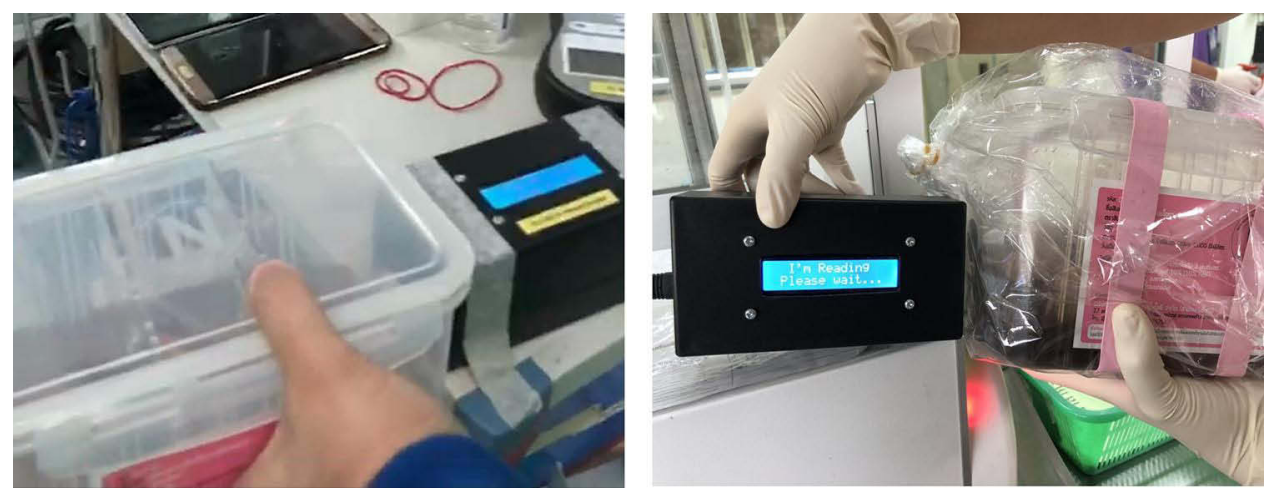

Figure $5 \mathrm{~A}$ breast specimen container is scanned by the sensor reader at the OR (left picture), and again by the pathology laboratory (right picture).

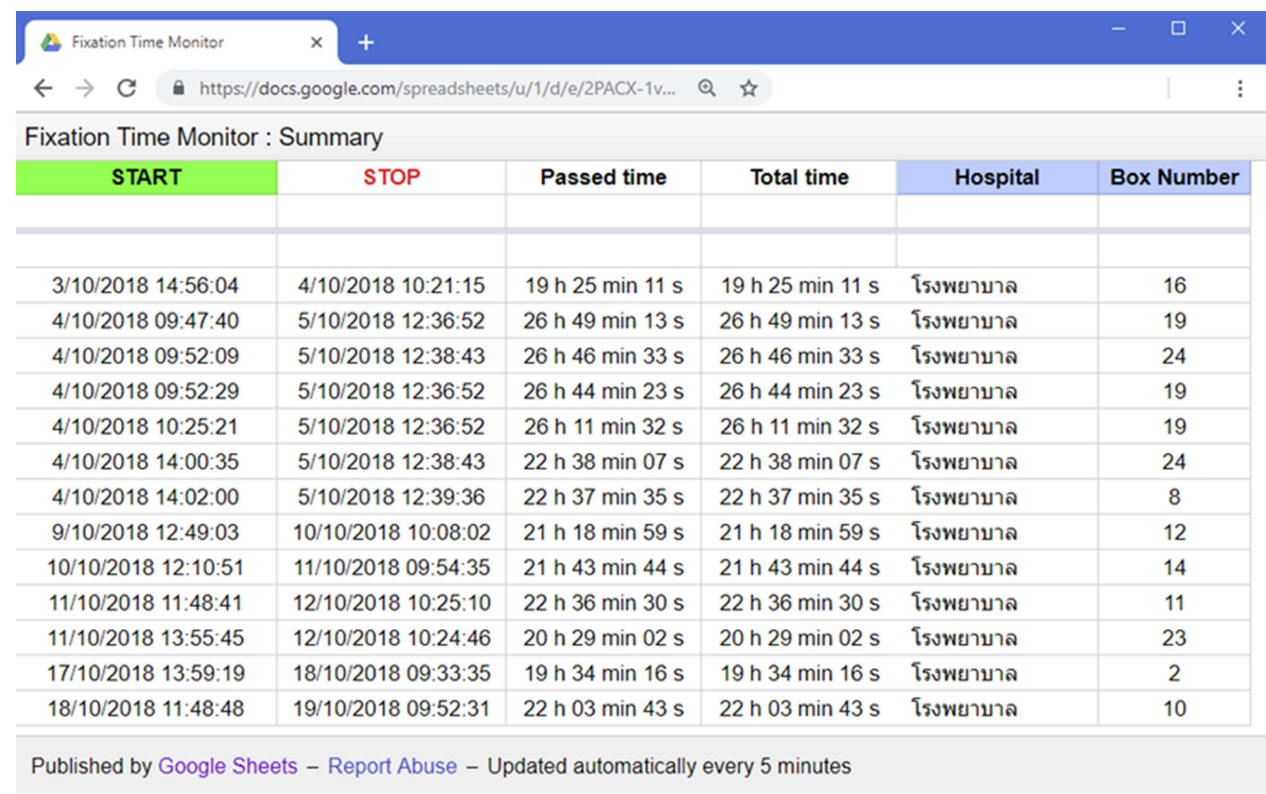

Figure 6 Fixation time monitoring, using a web-based application system.

cases. This was made possible through a successful collaboration with the former president of the Royal Committee of Surgeons of Thailand (Prof. Vajarabhongsa Bhudhisawasdi) who advocated for quality breast cancer biomarker reporting, particularly for hospitals in Northeastern Thailand.

In 2013, a pilot study was carried out in two Northeastern provinces of Kalasin and Roi Et hospitals, where surgeons agreed to collaborate and implement the innovation. These two hospitals sent their breast specimens to Chiang Mai (the largest city in Northern Thailand and the capital of Chiang Mai province) and Bangkok for pathology, with an average geographic distance of 300-400 miles. It should be noted that in addition to poor tissue fixation and adverse biomarker testing qualities, the turn-around time for reporting breast cancers from these two provinces were a concern to the surgeons and oncologists. The key performance indicator of breast cancer care in the country, supported and prioritized by the Thai Government, required a maximum duration of 2 weeks for issuing a pathology report post-biopsy and access to treatment within 4 weeks after the pathology report. This was certainly not the case in these two provinces, which further led to their selection in the pilot phase.

An educational orientation session with surgeons, OR nursing staff, and pathologists in each hospital was conducted. The orientation session included an hour workshop and an online video training regarding pre-analytic factors and logistical aspects of the project including the use of the container, slicing, orientation, and handling of breast surgical specimens. A post-training assessment tool was 
developed, requiring a passing score of at least $70 \%$ for surgeons and OR nursing staff and $80 \%$ for pathologists. It should be noted that all pathology laboratories participating in the project (including the pilot and subsequent laboratories) were required to be certified in breast cancer biomarker testing and accredited by the Royal Committee of Pathologist of Thailand.

Specialized breast containers and breast surgical requisition forms were provided to the two pilot hospitals and it was decided to redirect breast specimens from these two provinces to KKU Pathology Department at Srinagarind Hospital, with an average distance of 40-70 miles. The shorter geographic distance coupled with the use of the specialized container resulted in faster turn-around time, improved tissue fixation quality, and accurate biomarker results (unpublished data).

Subsequent to the implementation of the pilot project in the two Northeastern provinces and the success of our initiative in addressing breast cancer care disparity in Thailand, it received a national recognition and resulted in the inclusion of many additional hospitals from across the country. It is worth noting that a clear demand by surgeons and oncologists from different parts of the country in accessing timely pathology reports and quality biomarker testing helped expand the mandate. In fact, Pathum Raksa project was subsequently supported and endorsed by the Thai Breast Disease Society (TBS) in 2017, which resulted in national clinical practice guideline change, to adopt serial sectioning of breast specimens prior to sending to pathology laboratories. The support from the TBS also facilitated the expansion of the project across the nation, by allowing hospital administrators to access, adopt, and utilize project resources. Thus, cancer centers (university, government, and army) and community hospitals were all able to access the program and its resources. This also included private pathology laboratories mainly located in Bangkok, which are mostly the outsource laboratories from the hospitals that have access to the program.

Since the implementation of Pathum Raksa project in 2013, 19 hospitals across the country have officially joined the initiative, of which 6 agreed to share their data. Figure 7 presents the geographic distribution of participating hospitals across Thailand.

\section{KKU and Udonthani Hospitals}

Of all 19 participating hospitals, six agreed to share their data (Table 2), resulting in a total of 902 patients with



Figure 7 Geographic distribution of 19 participating hospitals using Pathum Raksa containers.

breast cancer surgeries (ie, mastectomy) over a 6-year study period (2015-2020). The data on pre- and postPathum Raksa was only available for KKU and Udonthani hospitals in Northeast Thailand, and as such these two hospitals were included in the analysis. The data was collected from 2015 to 2020, including 3 years prePathum Raksa (2015-2017) and 3 years post-Pathum Raksa (2018-2020), and a comparative analytic study was conducted.

A total of 595 patients with primary invasive mammary carcinoma, who underwent surgery were enrolled (405 from KKU and 190 from Udonthani hospitals). Biomarker testing was carried out in-house at KKU, while in Udonthani hospital specimens were tested at 


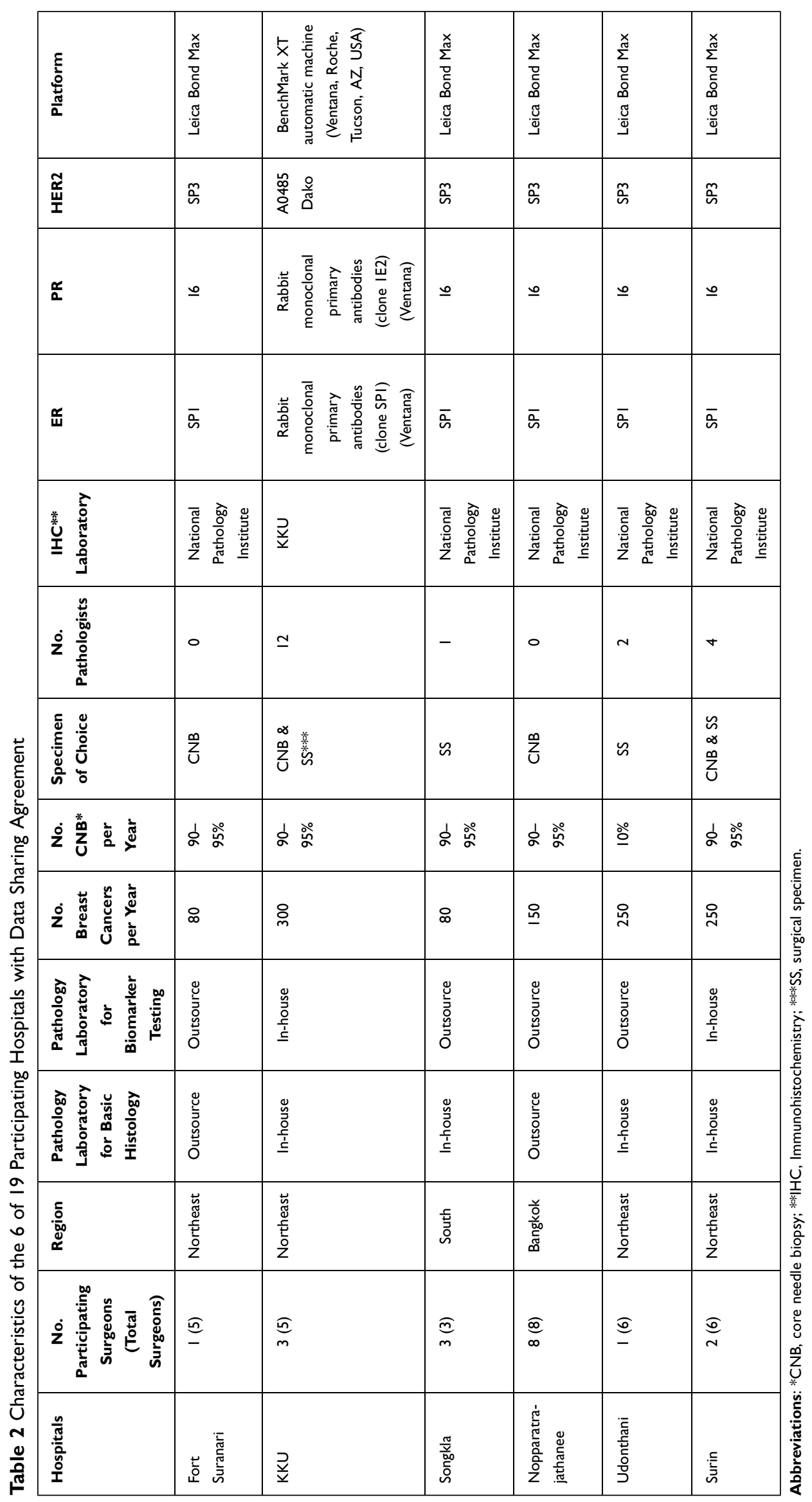


the National Pathology Institute, a government-based pathology laboratory in the capital Bangkok. The immunohistochemistry platform used at KKU was Ventana, whereas Leica was used in Udonthani. Table 2 shows the antibodies utilized at each immunohistochemistry laboratory.

Tumors were considered positive for ER and PR when at least $1 \%$ of the tumor cells showed unequivocal nuclear staining according to ASCO/CAP guidelines. ${ }^{11}$ HER2-neu was scored according to the pattern of membranous staining and percentage of stained malignant cells as follows: 0 , no staining or faint incomplete staining in $\leq 10 \%$ of cells; $1+$, faint incomplete staining in $>10 \%$ of cells; $2+$, weak to moderate complete staining in $>10 \%$ of cells; and $3+$, strong complete staining in $>10 \%$ of cells. Only score $3+$ was considered positive. The fraction of proliferating cells was based on a count of at least 500 tumor cells. The Ki67 values were expressed as the percentage of positive (nuclear staining) cells in each case. Cases with $>15 \%$ positive nuclei were classified as high Ki67 expression, and those with $<15 \%$ were classified as low Ki67 expression. $^{12,13}$

We used the clinicopathological surrogate definitions of breast cancer subtypes adopted by the 13th St. Gallen International Breast Cancer Conference (2013) Expert Panel, based on immunohistochemical measurements of ER, PR, HER2-neu, and Ki67 with in situ hybridization confirmation where appropriate. ${ }^{14}$ This included luminal A, with hormone receptor expression, without HER2-neu expression and low Ki67; luminal B, with hormone receptor and with HER2-neu expressions or high Ki67; HER2enriched, without hormone receptor expression and with HER2-neu expression; and triple-negative, without hormone receptor or HER2-neu expressions. It should be noted that Ki67 proliferation index was consistently examined for the KKU specimens, while for the Udonthani samples; it was mainly not carried out. Thus, we did not include Ki67 labeling index to determine breast cancer subtypes for the Udonthani specimens. Selected equivocal HER2-neu (score 2+) at KKU were further analyzed by dual in situ hybridization (DISH) assay. This is because in KKU biomarker testing is performed on both core biopsies and surgical specimens as per institutional policy; thus, depending on pertinent clinical indications DISH testing was performed on some of equivocal HER2-neu. On the other hand, we have no data available on equivocal HER2neu at Udonthani hospital.

\section{Statistical Analysis}

The values of continuous parameters were calculated as means \pm standard deviation (SD). Pearson's $\chi^{2}$ test was used for categorical variables. All tests were two-tailed, and $p<0.05$ was considered the level of statistical significance. All descriptive and inferential statistical analyses were carried out using the Statistical Package for the Social Sciences (SPSS), version 19.0 (Chicago, IL, USA).

\section{Results}

Mean $( \pm \mathrm{SD})$ patient age at KKU hospital was $55 \pm 10.9$ years (median 55 years), ranging from 26 to 92 years. The corresponding figure for Udonthani hospital was $53.5 \pm 11.3$ years (median 53 years), ranging from 26 to 82 years. At KKU, 2 of 405 patients were male, while there was only one male patient out of 190 at Udonthani hospital. The clinicopathological characteristics of patients in KKU and Udonthani hospitals are presented in Table 3.

Table 4 shows the distribution of biomarker testing preand post-Pathum Raksa. The rate of ER+ breast cancers at KKU hospital trended to increase from $59.3 \%$ to $65.0 \%$. Similarly, there was increased in rate of ER+ breast cancers at Udonthani hospital, from $58.3 \%$ 63.6\%. There were also increased rates of $\mathrm{PR}+$ breast cancers in both hospitals (the increased rate for Udonthani was statistically significant, from $43.7 \%$ to $59.1 \%, p=0.040$ ). The rate of HER $2+$ breast cancers in both hospitals were markedly increased from $16.9 \%$ to $28.0 \%(p=0.001)$ for $\mathrm{KKU}$, and trended to increased for Udonthani from $22.3 \%$ to $24.7 \%$ ( $p=0.635$ ). Interestingly, the rate of equivocal HER2-neu (score 2+) was particularly decreased for KKU breast cancers from $35.6 \%$ to $15.9 \%(p=0.001)$. The corresponding figure for Udonthani hospital was slightly decreased from $10.7 \%$ to $7.1 \%(p=0.635)$.

Table 5 shows the distribution of surrogate breast cancer subtypes pre- and post-Pathum Raksa. During the study period, luminal A/B was the most common breast cancer subtype in KKU and Udonthani (both pre- and post-Pathum Raksa). The rate of triple-negative breast cancers in both hospitals were significantly decreased from $26.9 \%$ to $12.7 \%$ in $\mathrm{KKU}(p=0.02)$, while it trended to decrease from $22.8 \%$ to $16.2 \%$ in Udonthani ( $p=0.48$ ). The rate of HER2-enriched breast cancers remained constant in Udonthani, while it increased in KKU after the implementation of Pathum Raksa project (from 13.5\% to $20.1 \%, p=0.33)$. 
Table 3 Clinicopathological Characteristics of Breast Cancer Patients in KKU and Udonthani Hospitals

\begin{tabular}{|c|c|c|c|}
\hline \multirow[t]{3}{*}{ Age (Year), Median (Range) } & Total & KKU & Udonthani \\
\hline & No. (\%) & No. (\%) & No. (\%) \\
\hline & $54(26-92)$ & 55 (26-92) & $53(26-82)$ \\
\hline$\leq 39$ & $52(8.7 \%)$ & $31(7.7 \%)$ & $21(11.1 \%)$ \\
\hline $40-49$ & $147(24.7 \%)$ & $96(23.7 \%)$ & $5 \mathrm{I}(26.8 \%)$ \\
\hline $50-59$ & $198(33.3 \%)$ & 137 (33.8\%) & $61(32.1 \%)$ \\
\hline 60-69 & $140(23.5 \%)$ & $101(24.9 \%)$ & $39(20.5 \%)$ \\
\hline$\geq 70$ & $58(9.7 \%)$ & 40 (9.9\%) & 18 (9.5\%) \\
\hline $\mathrm{n}$ & 595 & 405 & 190 \\
\hline \multicolumn{4}{|l|}{ Site } \\
\hline Left & 309 (51.9\%) & $211(52.1 \%)$ & $98(51.6 \%)$ \\
\hline Right & $285(47.9 \%)$ & $194(47.9 \%)$ & $\mathrm{I}(0.5 \%)$ \\
\hline Left and Right & I (0.2\%) & - & 91 (47.9\%) \\
\hline $\mathrm{n}$ & 595 & 405 & 190 \\
\hline \multicolumn{4}{|l|}{ Type of specimen } \\
\hline Mastectomy & $102(17.1 \%)$ & $98(24.2 \%)$ & $4(2.1 \%)$ \\
\hline Modified radical mastectomy & $477(80.2 \%)$ & 291 (71.9\%) & $186(97.9 \%)$ \\
\hline Wide excision & $16(2.7 \%)$ & $16(4.0 \%)$ & $0(0 \%)$ \\
\hline $\mathrm{n}$ & 595 & 405 & 190 \\
\hline \multicolumn{4}{|l|}{ Tumor size (cm.) } \\
\hline$<2$ & 147 (24.7\%) & 114 (28.1\%) & $33(17.4 \%)$ \\
\hline $2-5$ & 387 (65.0\%) & $231(57.0 \%)$ & $156(82.1 \%)$ \\
\hline$>5$ & $61(10.3 \%)$ & $60(14.8 \%)$ & $\mathrm{I}(0.5 \%)$ \\
\hline $\mathrm{n}$ & 595 & 405 & 190 \\
\hline \multicolumn{4}{|l|}{ Pathological type } \\
\hline Invasive ductal carcinoma of no special type & $564(94.8 \%)$ & 379 (93.6\%) & 185 (97.4\%) \\
\hline Invasive lobular carcinoma & $11(1.8 \%)$ & $10(2.5 \%)$ & I $(0.5 \%)$ \\
\hline Invasive mucinous carcinoma & $10(1.7 \%)$ & $8(2.0 \%)$ & $2(1.1 \%)$ \\
\hline Other & $10(1.7 \%)$ & $8(2.0 \%)$ & $2(1.1 \%)$ \\
\hline $\mathrm{n}$ & 595 & 405 & 190 \\
\hline \multicolumn{4}{|l|}{ Histologic grade } \\
\hline Grade I & $51(8.6 \%)$ & 37 (9.1\%) & 14 (7.4\%) \\
\hline Grade 2 & $312(52.4 \%)$ & $207(51.1 \%)$ & $105(55.3 \%)$ \\
\hline Grade 3 & $232(39.0 \%)$ & 161 (39.8\%) & $71(37.4 \%)$ \\
\hline$n$ & 595 & 405 & 190 \\
\hline \multicolumn{4}{|l|}{ Lymphovascular space invasion } \\
\hline Negative & 247 (4I.5\%) & 228 (56.3\%) & 110 (57.9\%) \\
\hline Positive & 338 (56.8\%) & 167 (4I.2\%) & 80 (42.1\%) \\
\hline$N / A$ & $10(1.7 \%)$ & $10(2.5 \%)$ & - \\
\hline$n$ & 595 & 405 & 190 \\
\hline \multicolumn{4}{|l|}{ Lymph node positive } \\
\hline 0 & 361 (60.7\%) & $203(50.1 \%)$ & I58 (83.2\%) \\
\hline $1-3$ & $130(21.9 \%)$ & 107 (26.4\%) & $23(12.1 \%)$ \\
\hline $4-9$ & 47 (7.9\%) & $4 \mid(10.1 \%)$ & $6(3.2 \%)$ \\
\hline$\geq 10$ & 27 (4.5\%) & 24 (5.9\%) & $3(1.6 \%)$ \\
\hline N/A & $30(5 \%)$ & $30(7.4 \%)$ & - \\
\hline
\end{tabular}


Table 3 (Continued).

\begin{tabular}{|l|c|c|c|}
\hline \multirow{2}{*}{ Age (Year), Median (Range) } & Total & KKU & Udonthani \\
\cline { 2 - 4 } & No. (\%) & No. (\%) & No. (\%) \\
\cline { 2 - 4 } & $\mathbf{5 4 ( 2 6 - 9 2 )}$ & $\mathbf{5 5}(\mathbf{2 6 - 9 2})$ & 190 \\
\hline TNM staging (8th AJCC/UICC) & $595)$ & \\
IA & & 405 & $28(14.7 \%)$ \\
IB & $98(16.5 \%)$ & $70(17.3 \%)$ & $2(1.1 \%)$ \\
IIA & $28(4.7 \%)$ & $26(6.4 \%)$ & $129(67.9 \%)$ \\
IIB & $239(40.1 \%)$ & $110(27.2 \%)$ & $22(11.6 \%)$ \\
IIIA & $108(18.2 \%)$ & $86(21.2 \%)$ & $6(3.2 \%)$ \\
IIIB & $64(10.8 \%)$ & $58(14.3 \%)$ & $0(0 \%)$ \\
IIIC & $0(0 \%)$ & $0(0 \%)$ & $3(1.6 \%)$ \\
IV & $28(4.7 \%)$ & $25(6.2 \%)$ & $0(0 \%)$ \\
N/A & $0(0 \%)$ & $0(0 \%)$ & - \\
\hline n & $30(5 \%)$ & $30(7.4)$ & 190 \\
\hline
\end{tabular}

Abbreviation: N/A, data not available.

Table 4 Biomarker Breast Cancer Testing Pre- and Post-Pathum Raksa in KKU and Udonthani Hospitals, 20I5-2020

\begin{tabular}{|c|c|c|c|c|c|c|c|}
\hline \multirow[t]{2}{*}{ Biomarker } & \multirow[t]{2}{*}{ Status } & \multicolumn{3}{|c|}{ KKU } & \multicolumn{3}{|c|}{ Udonthani } \\
\hline & & $\begin{array}{l}\text { Pre-Pathum } \\
\text { Raksa }\end{array}$ & $\begin{array}{c}\text { Post-Pathum } \\
\text { Raksa }\end{array}$ & $p$-value & $\begin{array}{c}\text { Pre-Pathum } \\
\text { Raksa }\end{array}$ & $\begin{array}{l}\text { Post-Pathum } \\
\text { Raksa }\end{array}$ & $p$-value \\
\hline ER & $\begin{array}{l}\text { Positive } \\
\text { Negative }\end{array}$ & $\begin{array}{l}35(59.3 \%) \\
24(40.7 \%)\end{array}$ & $\begin{array}{l}225(65.0 \%) \\
121(35.0 \%)\end{array}$ & 0.398 & $\begin{array}{l}60(58.3 \%) \\
43(41.7 \%)\end{array}$ & $\begin{array}{l}56(63.6 \%) \\
32(36.4 \%)\end{array}$ & 0.498 \\
\hline PR & $\begin{array}{l}\text { Positive } \\
\text { Negative }\end{array}$ & $\begin{array}{l}29(49.2 \%) \\
30(50.8 \%)\end{array}$ & $\begin{array}{l}190(54.9 \%) \\
156(45.1 \%)\end{array}$ & 0.412 & $\begin{array}{l}45(43.7 \%) \\
58(56.3 \%)\end{array}$ & $\begin{array}{l}52(59.1 \%) \\
36(40.9 \%)\end{array}$ & 0.040 \\
\hline HER2-neu & $\begin{array}{l}\text { Positive } \\
\text { Negative } \\
\text { Equivocal }\end{array}$ & $\begin{array}{l}10(16.9 \%) \\
28(47.5 \%) \\
21(35.6 \%)\end{array}$ & $\begin{array}{c}97(28.0 \%) \\
194(56.1 \%) \\
55(15.9 \%)\end{array}$ & 0.001 & $\begin{array}{l}23(22.3 \%) \\
69(67.0 \%) \\
11(10.7 \%)\end{array}$ & $\begin{array}{c}21 \text { ( } 24.7 \%) \\
58(68.2 \%) \\
6(7.1 \%)\end{array}$ & 0.635 \\
\hline
\end{tabular}

The distribution of surrogate breast cancer subtypes by age group in each hospital (pre- and post-Pathum Raksa) is shown in Figures 8 and 9. The rate of luminal tumors (luminal A/B) increased by age in Udonthani, while it was relatively constant across various age groups in KKU. Similarly, the rate of triple-negative cancers decreased by age in Udonthani.

\section{Discussion}

Breast cancer continues to be a growing public health challenge in Thailand, with its incidence significantly increased in all regions of the country. ${ }^{2}$ The rate of breast cancer in Northeastern Thailand, is 19.4 cases per 100,000 population. This rate is lower than other regions such as the Northern, Central, and Southern regions, with rates of

Table 5 Surrogate Breast Cancer Subtypes Pre- and Post-Pathum Raksa in KKU and Udonthani Hospitals, 20I5-2020

\begin{tabular}{|c|c|c|c|c|c|c|}
\hline \multirow[t]{2}{*}{ Subtypes } & \multicolumn{3}{|c|}{ KKU } & \multicolumn{3}{|c|}{ Udonthani } \\
\hline & Pre-Pathum Raksa & Post-Pathum Raksa & $p$-value & Pre-Pathum Raksa & Post-Pathum Raksa & p-value \\
\hline Luminal $A / B$ & $31(59.6)$ & $223(67.2)$ & 0.62 & $55(59.8 \%)$ & $53(66.3 \%)$ & 0.67 \\
\hline HER2-enriched & 7 (I3.5\%) & $67(20.1 \%)$ & 0.33 & $16(17.4 \%)$ & I4 (I7.5\%) & 0.85 \\
\hline Triple-negative & I4 (26.9\%) & 42 (I2.7\%) & 0.02 & 21 (22.8\%) & 13 (I6.2\%) & 0.48 \\
\hline
\end{tabular}




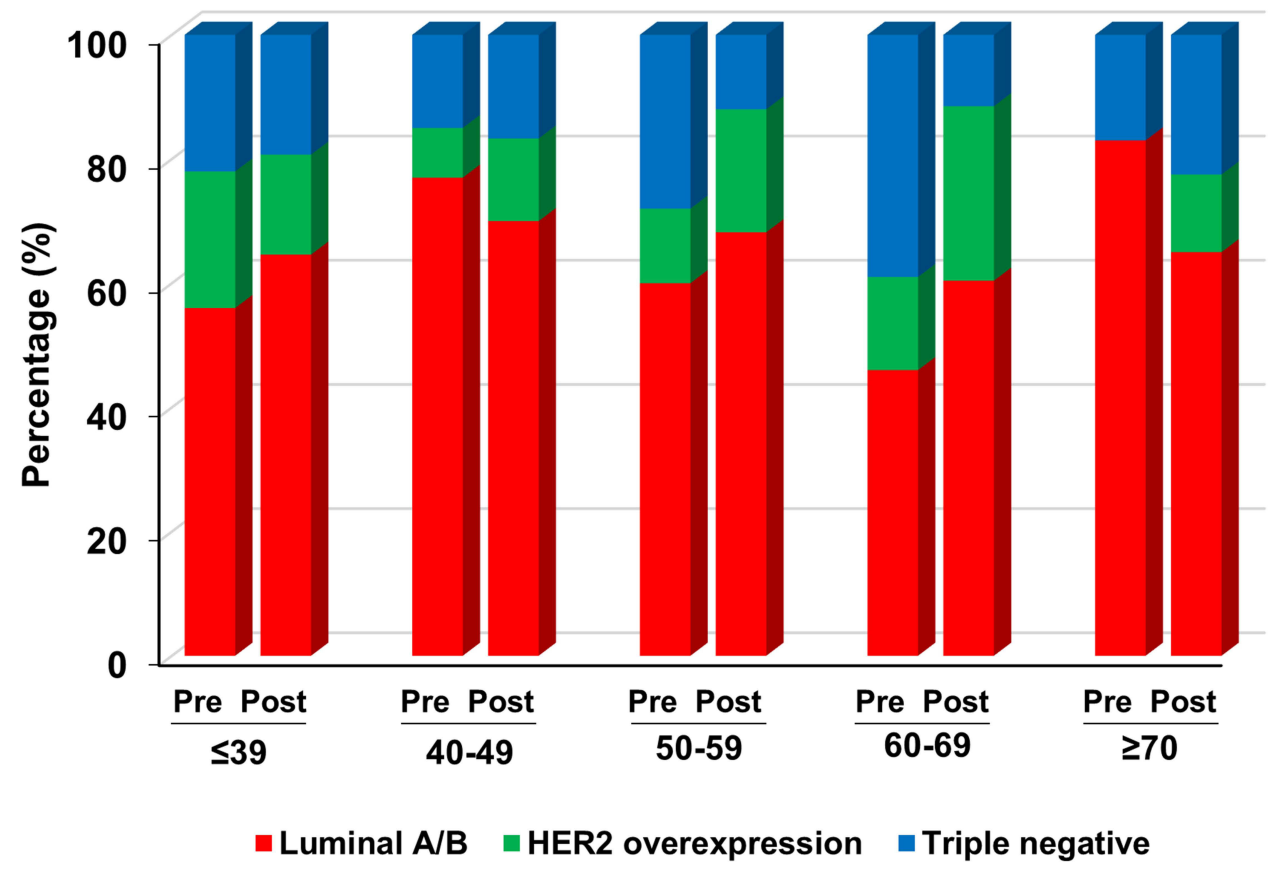

Figure 8 Age-specific distribution of surrogate breast cancer subtypes in KKU pre- and post-Pathum Raksa (2015-2020).

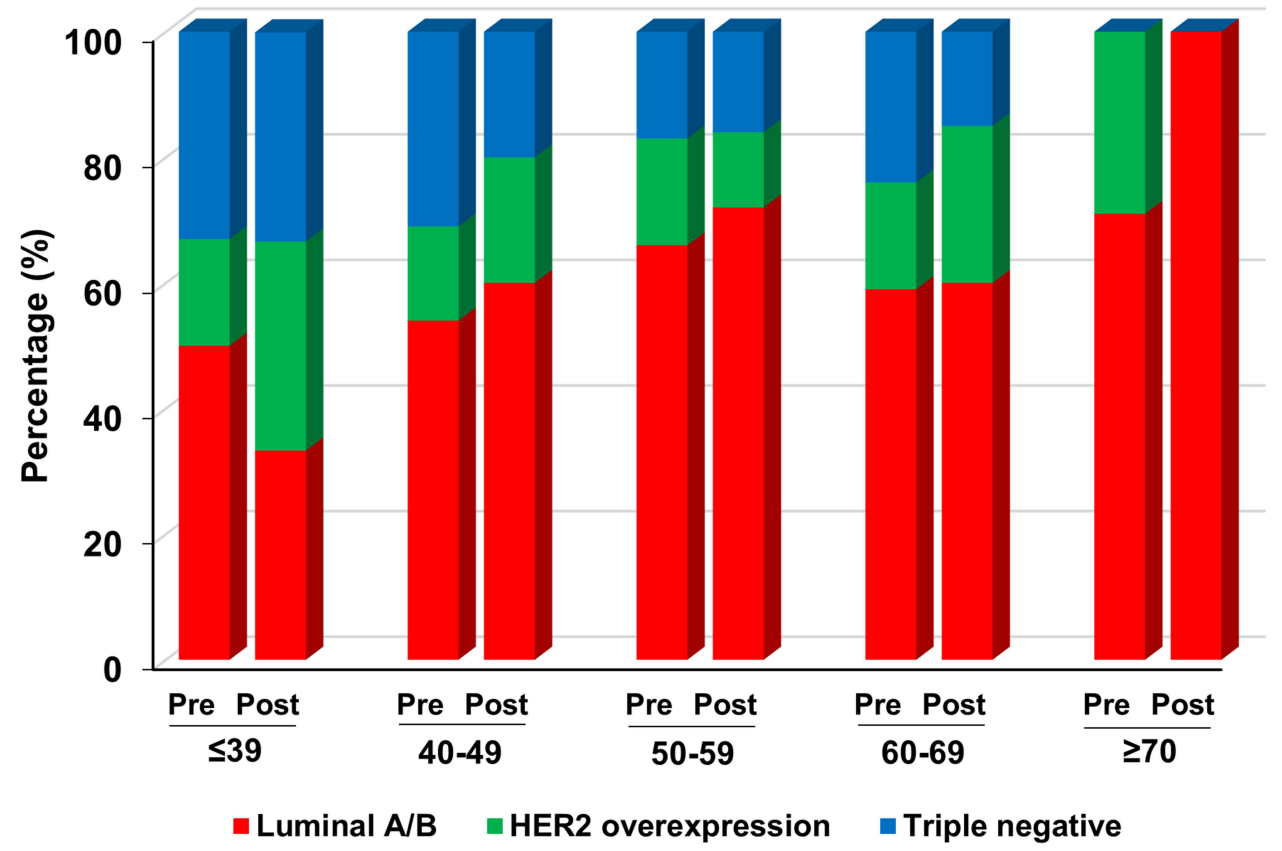

Figure 9 Age-specific distribution of surrogate breast cancer subtypes in Udonthani pre- and post-Pathum Raksa (2015-2020).

32.4, 33.9, and 27.4 cases per 100,000 population, respectively. ${ }^{15}$ However, it is expected to increase and become comparable to other regions by $2030 .{ }^{15}$ On the other hand, the rate of active practicing pathologists per 100,000 population in this region is one of the lowest in the country ( 0.2 in Northeast vs 3.8 in Bangkok per 100,000 population).
Biomarker testing (ER/PR/HER2-neu) is an important prognostic and predictive indicator in the management of breast cancer patients, and is included in the ASCO/CAP treatment guidelines. ${ }^{5}$ Patients with ER+ tumors generally have a better prognosis and survive longer than patients with ER- tumors. ${ }^{16}$ Patients with receptor positive tumors $(\mathrm{ER}+/ \mathrm{PR}+)$ are more likely to be offered adjuvant 
endocrine therapy and also more likely to benefit from that therapy. ${ }^{16,17}$ Thus, accurate assessment of biomarkers is critical for the optimal treatment of breast cancer.

ER, PR, and HER2-neu are thermolabile proteins whose expressions can be altered by prolonged exposure to room temperature prior to fixation or the length of fixation, and likely by fixation type. ${ }^{16}$ There are a number of studies from Thailand, which examined breast cancer biomarker profiles in various regions (Table 6). ${ }^{10,18-25}$ Similar to the index study conducted by Koonmee et al, ${ }^{10}$ the majority of the Thai studies showed a rather low ER+ and higher than expected triple-negative breast cancer rates among Thai women. The range of ER+ cancers was as low as $50 \%$, and the triplenegative rate ranged from $13 \%$ to $23 \%$. The ER+ breast cancer is the most common surrogate subtype with an average global rate of $79-84 \%$, while the triple-negative breast cancer rate is expected at approximately $10-15 \% .^{5}$

In interpreting data on breast biomarkers in Thai studies (Table 6), it is important to note that the immunohistochemical biomarker diagnostic criteria changed over time. ASCO/CAP changed the criteria for $\mathrm{ER}+\mathrm{PR}+$ from $10 \%$ to $1 \%$ threshold, and for HER2-neu+ (score 3+) from 30\% to 10\% for cut-off value. Despite considering the above-mentioned changes in biomarker diagnostic criteria, the issue of low $\mathrm{ER}+$ and high triple-negative breast cancers, particularly in the North and Northeastern Thailand, has remained a clinical and pathological quality issue, which negatively impacts patient care. We believe that one of the main pre-analytical causes of high falsenegative biomarker breast testing in this region is related to poor tissue fixation. Pathum Raksa project was launched in 2015, to specifically target specific pre-analytical factors through innovation to address the breast cancer care disparity in the country. This included designing an innovative process through various methods addressing the handling of surgical specimens based on local needs and available resources in Thailand, where population demographics, geographical access to care, hospital manpower, and pathology laboratory expertise are not equally distributed.

The design and proper engineering of the specialized breast container in this project was innovative and served

Table 6 Thai Studies Examining Breast Cancer Biomarkers

\begin{tabular}{|c|c|c|c|c|c|c|c|c|}
\hline Study & Region & Criteria & Cases & $\begin{array}{l}\text { Study } \\
\text { Period }\end{array}$ & ER & PR & $\begin{array}{l}\text { HER2- } \\
\text { Enriched }\end{array}$ & $\begin{array}{c}\text { Triple- } \\
\text { Negative }\end{array}$ \\
\hline Chirappapha et al ${ }^{18}$ & Bangkok & $\begin{array}{c}\text { ER/PR >10\%, } \\
\text { HER2 Score } 3 \\
+\end{array}$ & 256 & $2002-2006$ & N/A* & $N / A$ & $\mathrm{~N} / \mathrm{A}$ & $\begin{array}{l}23 \%(<60 Y) \\
14 \%(>60 Y)\end{array}$ \\
\hline $\begin{array}{l}\text { Chottanapund } \\
\text { et al }{ }^{19}\end{array}$ & Bangkok & $\mathrm{N} / \mathrm{A}$ & 95 & $2011-2013$ & $60 \%$ & $\mathrm{~N} / \mathrm{A}$ & $\begin{array}{c}40 \% \\
\text { (score } 2 \\
+/ 3+\text { ) }\end{array}$ & $19 \%$ \\
\hline $\begin{array}{l}\text { Sujarittanakarn } \\
\text { et } \mathrm{al}^{24}\end{array}$ & $\begin{array}{l}\text { Central (Pathum Thani - } \\
\text { Bangkok metropolitan) }\end{array}$ & $\begin{array}{l}E R / P R>1 \% \\
H E R 2>10 \%\end{array}$ & 99 & $201 I-2015$ & $74.7 \%$ & $71.7 \%$ & $26.3 \%$ & $N / A$ \\
\hline Laohavinij et al ${ }^{21}$ & Bangkok & $\begin{array}{l}\text { ER/PR> } 1 \% \\
\text { HER2 }>10 \%\end{array}$ & 232 & $2005-2013$ & LuA** $48.7 \%$ & $\begin{array}{l}\text { LuB*** } \\
14.3 \%\end{array}$ & $18.5 \%$ & $18.5 \%$ \\
\hline Sripan et $\mathrm{al}^{23}$ & $\begin{array}{l}\text { North (Chiang Mai } \\
\text { province) }\end{array}$ & $\begin{array}{l}\text { ER/PR> } 1 \% \\
\text { HER2 }>10 \%\end{array}$ & 3228 & $2004-2013$ & LuA $39 \%$ & $\begin{array}{l}\text { LuB } \\
22 \%\end{array}$ & $21 \%$ & $18 \%$ \\
\hline Koonmee et $\mathrm{al}^{10}$ & Northeast (Khon Kaen) & $\begin{array}{c}\text { ER/PR >10\%, } \\
\text { HER2 Score } 3 \\
+\end{array}$ & 294 & 2004-2006 & LuA $51 \%$ & LuB $8 \%$ & $19 \%$ & $22 \%$ \\
\hline Chuthapisith et $\mathrm{al}^{20}$ & Bangkok & $\mathrm{N} / \mathrm{A}$ & 321 & $2009-2010$ & $71.6 \%$ & $64.5 \%$ & $26 \%$ & $15 \%$ \\
\hline Virani et $\mathrm{al}^{25}$ & $\begin{array}{l}\text { South (Songkhla } \\
\text { Province) }\end{array}$ & $N / A$ & 635 & $2010-2012$ & LuA $46 \%$ & $\begin{array}{l}\text { LuB } \\
28 \%\end{array}$ & $13 \%$ & $13 \%$ \\
\hline $\begin{array}{l}\text { Lertsanguansinchai } \\
\text { et } \mathrm{al}^{22}\end{array}$ & Bangkok & $\begin{array}{c}\text { ER/PR }>10 \%, \\
\text { HER2 Score } 3 \\
+\end{array}$ & 576 & |995-200| & $53.4 \%$ & $42.1 \%$ & $N / A$ & N/A \\
\hline
\end{tabular}

Abbreviations: *N/A, data not available; **LuA, Luminal A; ***LuB, Luminal B. 
as one of the foundations in addressing poor breast tissue fixation. Engaging the surgical team in various parts of the country to join the project and to coordinate their efforts with pathology laboratories was also an instrumental step towards the success of this national innovation. As a result of this, there are currently 19 hospitals from 13 provinces across the country (South: 3 hospitals in 2 provinces, Northeast: 9 hospitals in 6 provinces, North: 2 hospitals in 2 provinces, and Central: 5 hospitals in 3 provinces) that have joined the Pathum Raksa project.

The main goal of tissue handling and preparation are/is to ensure adequate tissue preservation, which was successfully achieved in this project. Inaccurate results due to compromised tissue quality can lead to false positive or false negative results with therapeutic consequences that can harm patients and affect their eventual outcome. ${ }^{26}$ Fixation time often remains poorly controlled in general practice for the majority of cancers, ${ }^{27}$ but we were able to implement a system to effectively and efficiently monitor fixation time, using IoT concept in this project. We believe that collaboration between Surgery and Pathology Departments in various institutions across the country, to proactively transfer specimens to laboratories, has proven to be successful in achieving the goal of standardizing tissue handling rather than trying to expect or to push an already busy OR staff to deliver specimens in a more timely fashion.

In this study, we examined pre- and post-Pathum Raksa data from two hospitals (KKU and Udonthani) in Northeastern Thailand, to assess the impact of the project on key biomarker performance indicators. Both hospitals performed histologic examinations in-house. As for biomarker testing, breast specimens were carried out in-house in KKU, while they were outsourced to a governmentbased laboratory in the capital Bangkok for Udonthani, as the pathology laboratory in this province does not have immunohistochemistry infrastructure and capabilities.

Specimen of choice for biomarker testing in KKU is both core biopsy and surgical samples, while in Udonthani is predominantly (approximately 90\%) surgical specimens. The rate of $\mathrm{ER}+$ breast cancers in both hospitals increased on average 5\%, post-Pathum Raksa implementation. Similar findings were observed for PR testing. Our findings are consistent with improved ER/PR biomarker profile as the result of Pathum Raksa project implementation. Our research team recently compared the DNA quality of Formalin-Fixed Paraffin-Embedded (FFPE) tissue breast cancer specimens between those enrolled in Pathum Raksa project versus routine services at KKU laboratory, using real-time PCR method. This analysis showed significantly higher DNA quality of Pathum Raksa specimens than the routine services [unpublished data].

One of the most important key performance indicators examined in this study was the change in the rate of triplenegative breast cancers. As a result of the Pathum Raksa project, the rate of triple-negative breast cancers in KKU decreased $52.8 \%$. The corresponding figure for Udonthani showed a similar pattern with a $28.9 \%$ decrease in triplenegative breast cancer rate. At the population level, this translates to preventing inaccurate biomarker results and subsequent inappropriate treatments in approximately 50 women with breast cancer in Khon Kaen province and 15 in Udonthani province each year (data: Thai Cancer Registry). We believe this is one of the most important key clinical impacts of Pathum Raksa project by decreasing false-negative rates of triple-negative breast cancers, resulting in a significant change in the prognosis, treatment, and potentially survival of these women. It is worth noting that due to the invalidation of endocrine and target therapies, triple-negative breast cancer tends to be more aggressive and lethal than non-triple-negative breast cancer subtypes (luminal tumors). ${ }^{28,29}$

The rate of HER2-neu+ (score 3+) was also increased in both hospitals post-Pathum Raksa. This was more pronounced for KKU with over 65\% increase in HER2-neu+ (score $3+$ ). At the population level, it is projected that approximately 40 women with breast cancer in Khon Kaen province may qualify for HER2 targeted therapy (data: Thai Cancer Registry). Interestingly, the rate of equivocal HER2-neu (score 2+) in KKU decreased 54\% and the HER2-enriched rate increased approximately 50\%. This is a clinically significant finding since trastuzumab is the most common targeted therapy drug used to treat HER2-positive breast cancer patients. HER2-positive breast cancers consist of intrinsic molecular subtypes luminal A, luminal B, and HER2-enriched subtype, with the HER2-enriched subtype, has the function to activate of the EGFR-HER2 pathway. The previous study has shown that patients with the HER2-enriched subtype will benefit the most from certain therapeutic regimens, such as dual HER2 blockade. $^{30}$

As expected, luminal tumors were the most common breast cancer subtypes in this study, which is similar to other Thai studies ${ }^{10,15,21,23}$ and the global literature. ${ }^{31}$ Luminal B was found to be the most frequent breast cancer 
subtype in KKU both pre- and post Pathum Raksa, while luminal A cancers were the most common subtype in Udonthani. According to the 2013 St. Gallen Consensus ${ }^{14}$ the luminal B subtype accounted for nearly $40 \%$ of all breast cancers, which is similar to post-Pathum Raksa implementation in KKU (44\%). We further investigated this matter in a cohort of 74 breast core biopsies at KKU during the study period and found that $55.4 \%$ (41/ 74) of all were luminal B. We believe that the difference in the luminal tumor profile between the two provinces is due to the fact that Ki67 index data was not available in Udonthani (unlike KKU). This, as a limitation of the study, which may have resulted in the discrepant luminal breast cancer profile between the two provinces. Further analysis of the data in Udonthani, we found only six cases of breast cancers with Ki67 index, of which 2/6 (33\%) were luminal A and 4/6 (67\%) were luminal B. This further supports the above-mentioned possibility for such a discrepancy.

\section{Conclusions}

Pathum Raksa project is a national innovative initiative, which has significantly impacted the lives of Thai breast cancer patients. This project demonstrated a successful example of how a combined national public health vision with resourcestratified planning can address the issue of breast cancer care disparity in Thailand. As a result of this innovation, falsenegative rates of breast biomarkers have significantly decreased, resulting in significant change in the prognosis, treatment, and survival breast cancer women in Thailand.

\section{Ethics Approval and Informed Consent}

The study was conducted according to the guidelines of the Declaration of Helsinki, and approved by the Ethics Committee for Human Research, Khon Kaen University (HE601284) and written informed consent was obtained from all patients.

\section{Acknowledgments}

We would like to thank Prof. Vajarabhongsa Bhudhisawasdi, the former president of the Royal Committee of Surgeons of Thailand, Dr. Paiboon Pensuwan, Deputy Director of Roi Et hospital, Dr. Chanthit Phunlap, Head of Surgery Department, Roi Et hospital, and Dr. Thanasit Praipong, Deputy Director of Kalasin hospital, for their valuable support and assistance in managing the project since 2012.

\section{Author Contributions}

All authors contributed to data analysis, drafting and/or revising the article, gave final approval of the version to be published, agreed to the submitted journal, and agree to be accountable for all aspects of the work.

\section{Funding}

We would like to acknowledge the Deans of three Faculties of Medicine at Chiang Mai University, Prince of Songkla University, and Khon Kaen University for funding support of the project as well as the Thai Breast Diseases Society for providing funding to participating hospitals.

\section{Disclosure}

Dr Supinda Koonmee and Dr Krisada Prachumrasee report a Pretty Patent licensed to 9256 and a Pretty Patent licensed to 16424. Dr Sakkarn Sangkhamanon reports Pretty patent no. 9256 from the Department of intellectual property, Thailand, outside the submitted work; in addition, Dr Sakkarn Sangkhamanon reports Pretty patent no. 9256 with royalties paid to New Medical Technology company. The authors report no other potential conflicts of interest for this work.

\section{References}

1. Anderson BO, Ilbawi AM, Fidarova E, et al. The Global Breast Cancer Initiative: a strategic collaboration to strengthen health care for noncommunicable diseases. Lancet Oncol. 2021;22:578-581. doi:10.1016/ S1470-2045(21)00071-1

2. Virani S, Bilheem S, Chansaard W, et al. National and subnational population-based incidence of cancer in Thailand: assessing cancers with the highest burdens. Cancers. 2017;9(12):108. doi:10.3390/ cancers 9080108

3. Parra-Herran C, Romero Y, Milner D. Pathology and Laboratory Medicine in cancer care: a global analysis of national cancer control plans. Int J Cancer. 2021;148:1938-1947. doi:10.1002/ijc.33384

4. Anglade F, Milner DA, Brock JE. Can pathology diagnostic services for cancer be stratified and serve global health? Cancer. 2020;126 (Suppl 10):2431-2438. doi:10.1002/cncr.32872

5. Allison KH, Hammond MEH, Dowsett M, et al. Estrogen and progesterone receptor testing in breast cancer: American society of clinical oncology/College of American pathologists guideline update. Arch Pathol Lab Med. 2020;144:545-563. doi:10.5858/arpa.2019-0904-SA

6. Globocan: Cancer Today. The Global Cancer Observatory. Thailand: International Agency for Research on Cancer (IARC), World Health Organization (WHO); 2020.

7. Wattanasri N, Manoroma W, Viriyayudhagorn S. Laboratory accreditation in Thailand: a systemic approach. Am J Clin Pathol. 2010;134:534-540. doi:10.1309/AJCPZYY19WMKMAZT

8. Sampatanukul P, Chaiwun B, Wongwaisayawan S, et al. A two-phase study model for the standardization of HER2 immunohistochemical assay on invasive ductal carcinoma of the breast. J Med Assoc Thai. 2005;88:1680-1688. 
9. Metter DM, Colgan TJ, Leung ST, Timmons CF, Park JY. Trends in the US and Canadian pathologist workforces from 2007 to 2017. JAMA Netw Open. 2019;2:e194337. doi:10.1001/jamanetworkopen.2019.4337

10. Koonmee S, Sirithunyaporn S, Phanomsri E. Hormonal receptors status of breast cancer in Northeastern Thai women: an analysis of 241 cases at Srinagarind hospital. Srinagarind Med J. 2006;21:343-351.

11. Deyarmin B, Kane JL, Valente AL, et al. Effect of ASCO/CAP guidelines for determining ER status on molecular subtype. Ann Surg Oncol. 2013;20:87-93. doi:10.1245/s10434-012-2588-8

12. Engstrom MJ, Opdahl S, Hagen AI, et al. Molecular subtypes, histopathological grade and survival in a historic cohort of breast cancer patients. Breast Cancer Res Treat. 2013;140:463-473. doi:10.1007/ s10549-013-2647-2

13. Goldhirsch A, Ingle JN, Gelber RD, Coates AS, Thurlimann B, Senn HJ. Thresholds for therapies: highlights of the St Gallen International Expert Consensus on the primary therapy of early breast cancer 2009 . Ann Oncol. 2009;20:1319-1329. doi:10.1093/annonc/mdp322

14. Goldhirsch A, Winer EP, Coates AS, et al. Personalizing the treatment of women with early breast cancer: highlights of the St Gallen International Expert Consensus on the Primary Therapy of Early Breast Cancer 2013. Ann Oncol. 2013;24:2206-2223. doi:10.1093/ annonc/mdt303

15. Virani S, Chindaprasirt J, Wirasorn K, et al. Breast cancer incidence trends and projections in Northeastern Thailand. $J$ Epidemiol. 2018;28:323-330. doi:10.2188/jea.JE20170045

16. Nkoy FL, Hammond ME, Rees W, et al. Variable specimen handling affects hormone receptor test results in women with breast cancer: a large multihospital retrospective study. Arch Pathol Lab Med. 2010;134:606-612. doi:10.1043/1543-2165-134.4.606

17. Schrodi S, Braun M, Andrulat A, et al. Outcome of breast cancer patients with low hormone receptor positivity: analysis of a 15 -year population-based cohort. Ann Oncol. 2021;32(11):1410-1424. doi:10.1016/j.annonc.2021.08.1988

18. Chirappapha P, Sukarayothin T, Wasuthit Y, Suvikapalornkul R, Lertsithichai P, Kongdan Y. Disease-free probability and triple-negative breast cancer. Rama Med J. 2012;35:5-13. doi:10.33165/ rmj.2012.35.1.117663

19. Chottanapund S, Van Duursen MBM, Ratchaworapong K, Navasumrit P, Ruchirawat M, Van den Berg M. Androgen receptor expression in Thai breast cancer patients. Med Sci. 2016;4. doi:10.3390/medsci4030015

20. Chuthapisith S, Permsapaya W, Warnnissorn M, Akewanlop C, Sirivatanauksorn V, Prasarttong Osoth P. Breast cancer subtypes identified by the ER, PR and HER-2 status in Thai women. Asian Pac J Cancer Prev. 2012;13:459-462. doi:10.7314/apjcp.2012.13.2.459

21. Laohavinij S, Paul V, Maneenil K. Survival and prognostic factors of metastatic breast cancer. J Med Assoc Thai. 2017;100(Suppl 1):S16-26.

22. Lertsanguansinchai $\mathrm{P}$, Chottetanaprasith $\mathrm{T}$, Chatamra $\mathrm{K}$, et al. Estrogen and progesterone receptors status in Thai female breast cancer patients: an analysis of 399 cases at King Chulalongkorn Memorial Hospital. J Med Assoc Thai. 2002;85(Suppl 1):S193-202.

23. Sripan P, Sriplung H, Pongnikorn D, et al. Clinical subtypes of breast cancer in Thai women: a population-based study of Chiang Mai province. Asian Biomed. 2019;13:11-17. doi:10.1515/abm-2019-0034
24. Sujarittanakarn S, Himakhun W, Worasawate W, Prasert W. The case to case comparison of hormone receptors and HER2 status between primary breast cancer and synchronous axillary lymph node metastasis. Asian Pac J Cancer Prev. 2020;21:1559-1565. doi:10.31557/ APJCP.2020.21.6.1559

25. Virani S, Wetzel EC, Laohawiriyakamol S, et al. Ethnic disparity in breast cancer survival in southern Thai women. Cancer Epidemiol. 2018;54:82-89. doi:10.1016/j.canep.2018.02.007

26. Hicks DG, Boyce BF. The challenge and importance of standardizing pre-analytical variables in surgical pathology specimens for clinical care and translational research. Biotech Histochem. 2012;87:14-17. doi: $10.3109 / 10520295.2011 .591832$

27. Hewitt SM, Lewis FA, Cao Y, et al. Tissue handling and specimen preparation in surgical pathology: issues concerning the recovery of nucleic acids from formalin-fixed, paraffin-embedded tissue. Arch Pathol Lab Med. 2008;132:1929-1935. doi:10.1043/1543-2165132.12.1929

28. Costa RLB, Gradishar WJ. Triple-negative breast cancer: current practice and future directions. J Oncol Pract. 2017;13:301-303. doi:10.1200/JOP.2017.023333

29. Lian CL, Li GQ, Zhou P, Wang J, He ZY, Wu SG. Triple-negative breast cancer outcomes: does AJCC 8th staging improve chemotherapy decision-making. Breast. 2021;59:117-123. doi:10.1016/j. breast.2021.06.009

30. Llombart-Cussac A, Cortes J, Pare L, et al. HER2-enriched subtype as a predictor of pathological complete response following trastuzumab and lapatinib without chemotherapy in early-stage HER2-positive breast cancer (PAMELA): an open-label, single-group, multicentre, Phase 2 trial. Lancet Oncol. 2017;18:545-554. doi:10.1016/S1470-2045(17)30021-9

31. Acheampong T, Kehm RD, Terry MB, Argov EL, Tehranifar P. Incidence trends of breast cancer molecular subtypes by age and race/ethnicity in the US from 2010 to 2016. JAMA Netw Open. 2020;3:e2013226. doi:10.1001/jamanetworkopen.2020.13226

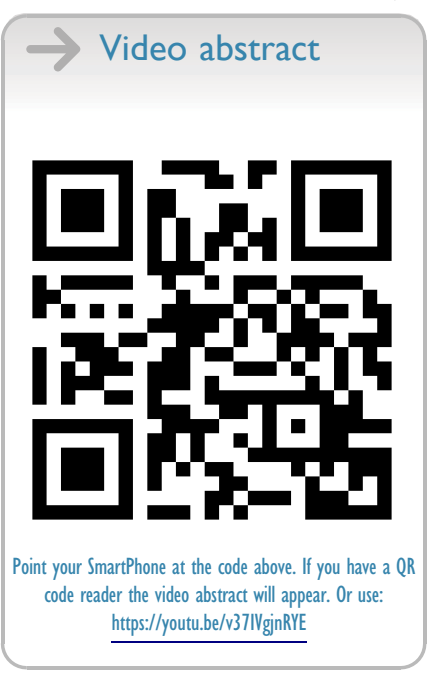

Cancer Management and Research is an international, peer-reviewed open access journal focusing on cancer research and the optimal use of preventative and integrated treatment interventions to achieve improved outcomes, enhanced survival and quality of life for the cancer patient.
The manuscript management system is completely online and includes a very quick and fair peer-review system, which is all easy to use. Visit http://www.dovepress.com/testimonials.php to read real quotes from published authors. 